\title{
JUURNAL.RU
}

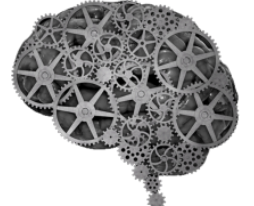

COMPANY GROUP "INTELLEKT"

Хабибуллин Р.М. Самарский национальный исследовательский университет имени академика С. П. Королёва

Самара, Россия

doi: 10.18411/1j2016-4-48

\section{Метод конечных элементов в расчёте конструкции солнечного паруса кар- касного типа на прочность}

Аннотация. Рассматривается метод конечных элементов для расчёта на прочность конструкции космического аппарата с солнечным парусом. Созданы геометрическая модель и конечно-элементная модель космического аппарата с солнечным парусом. Описаны возмущающие силы, действующие на парус. Проведён нелинейно-статический анализ конструкции космического аппарата с солнечным парусом каркасного типа.

Ключевые слова: космический аппарат, солнечный парус, метод конечных элементов, конечно-элементное моделирование, прочностной расчёт.

\section{Введение}

В настоящее время проявляется огромный интерес к исследовательским космическим миссиям, в особенности, к миссиям дистанционного зондирования Земли. Одним из наиболее эффективных способов снижения стоимости миссий считается использование новейших принципов движения аппаратов наблюдения в космическом пространстве. Одним из таких принципов полёта космических аппаратов является использование солнечного паруса в качестве движительной установки. Солнечный парус - это приспособление, которое предназначено для приведения в движение космического аппарата с помощью давления солнечного света. При использовании новых физических принципов и устройств всегда воз- 
никает вопрос - насколько надёжна данная установка, и сможет ли исследовательский аппарат выполнять свою при использовании новой технологии.Математическая модель движения космического аппарата с солнечным парусом подробно описана в [1], что подтверждает способность устройства функционировать на рабочей орбите. В данной работе предлагается рассмотреть проблему прочности устройства ипровести нелинейно-статический анализ конструкции космического аппарата с солнечным парусом.

\section{Метод конечных элементов}

МКЭиспользуется для решений вариационных задач. Чаще всего он представляет собой метод Ритца [2] или метод Бубнова-Галеркина[3].Основная характерная черта МКЭ является использование локальных базисных функций, то есть функций отличных от нуля только на части области определения.

МКЭ является одним из основных и наиболее эффективных методов решения дифференциальных уравнений с частными производными, а также интегральных уравнений, возникающих при решении задач прикладной физики(в том числе и задач расчета напряженно-деформированного состояния конструкций) [4]. Основным достоинством данного метода является возможность решения задач для конструкций любой формы и размеров.Аналитические методы решения не могут похвастаться достижением подобных результатов. Поэтому МКЭ является основным инструментом инженера для проведения расчётов на прочность. Более того, на основе рассматриваемого метода написаны коммерческие программы для проведения прочностных вычислений. Для правильного и эффективного применения таких программ необходимо как знакомство с их интерфейсом, так и хорошее знание математических основ метода и связанных с ними ограничений и источников ошибок (погрешностей) решения. Одной из таких программ является Femap от компанииSiemensPLMSoftware [5].

Работа в системе конечно-элементного моделирования осуществляется в несколько этапов: 
- определение объекта и предмета исследования;

- определение конструкционных особенностей объекта исследования, то есть тех элементов структуры объекта, поведение которых требуется изучить;

- определение особенностей агрессивной среды, в которой будет осуществляться деятельность объекта исследования;

- создание геометрической модели объекта исследования;

- разбиение геометрической модели объекта на конечные элементы;

- описание условий и возмущающих сил, действующих на объект исследования;

- выбор типа анализа структуры объекта;

- работа с результатами расчёта на прочность.

Далее рассматривается конечно-элементное моделирование конструкции космического аппарата с солнечным парусом.

\section{Конечно-элементное моделирование}

Конечно-элементное моделирование представляет собой разработку геометрической модели космического аппарата с солнечным парусом, разбиение модели на конечные элементы, описание внешних возмущений. Разработанную конечно-элементную модель в дальнейшем используют для расчёта на прочность.

Была разработана геометрическая модель, состоящая из трёх основных частей:

1) центральное тело - космический аппарат;

2) балки крепления солнечного паруса;

3) полотно солнечного паруса.

Космический аппарат является центром сосредоточенной массы, абсолютно жестко закреплен.Балки крепления солнечного паруса являются балочными элементами, которыекрепятся к центру сосредоточенной массы.Само полотно 
солнечного паруса состоит из четырёх лепестков трапециевидной формы. Углы трапеции полотна крепятся к концам выдвижных балок. Солнечный парус является оболочным элементом.

Элементам геометрической модели были присвоены материалы и свойства, предоставленные в табл. 1 .

Таблица 1

Описание элементов космического аппарата с солнечным парусом

\begin{tabular}{|c|c|c|}
\hline Элемент конструкции & Балка & Солнечный парус \\
\hline Материал & Углепластик & Каптон \\
\hline Модуль упругости, МПа & 67000 & 2500 \\
\hline Коэффициент Пуассона & 0,33 & 0,34 \\
\hline Плотность, кг $/ \mathrm{m}^{3}$ & 1550 & 1420 \\
\hline Толщина, м & $2 \cdot 10^{-3}$ & $5 \cdot 10^{-6}$ \\
\hline Длина, м & 10 & 14 \\
\hline
\end{tabular}

Геометрическая модель космического аппарата с солнечным парусом предоставлена на рис. 1. Геометрическая модель, разбитая на конечные элементы изображена на рис. 2.

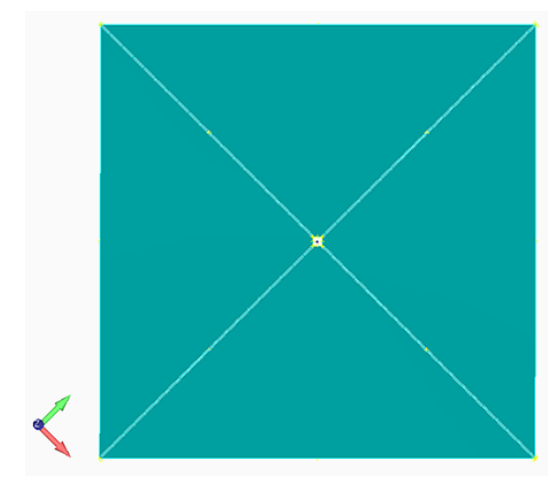

Рисунок 1 - Геометрическая модель

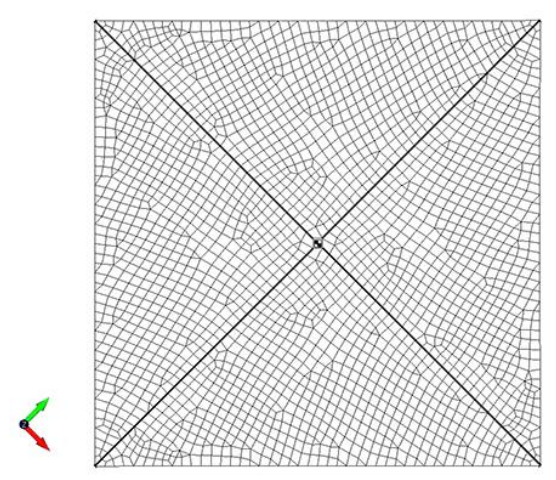

Рисунок 2 - Конечно-элементная модель

После разработки конечно-элементной модели следует описание внешних сил, действующие на солнечный парус. В данной работе учитывается влияние давления солнечного света. Рассматривается случай нагружениякосмического 
аппарата на орбите Земли на расстоянии от Солнца в $1,5 \cdot 10^{8}$ км. Нормаль отражающей поверхности солнечного паруса направлена на источник света, то есть вектор действия силы давления солнечного света направлен перпендикулярно поверхности полотна паруса.В данной области космического пространства действует давление солнечного света величиной $9,28 \cdot 10^{-6} \mathrm{H} / \mathrm{M}^{2}$.

\section{Результаты исследования конструкции солнечного паруса на прочность}

В рамках данной работы был проведен нелинейно-статический анализ с помощью метода конечных элементов конструкции солнечного паруса каркасного типа в системе конечно элементного моделирования Femap.После проведения нелинейно-статического анализа были получены следующие результаты:

- максимальные значения деформации солнечного паруса появились в центральной области внешней стороны полотна,максимальное значение деформации достигло 3,447 мм (рис. 3).

- максимальные значения напряжений возникли в области крепления солнечного паруса к балке,максимальное значение напряжения достигло 1300 Па (рис. 4).

В результате данного анализа был сделан вывод, что значения максимального напряжения и деформации, полученные в случае нагружениясолнечного паруса давлением солнечного света, не превысили критических значений. Солнечный парус способен функционировать на орбите Земли.

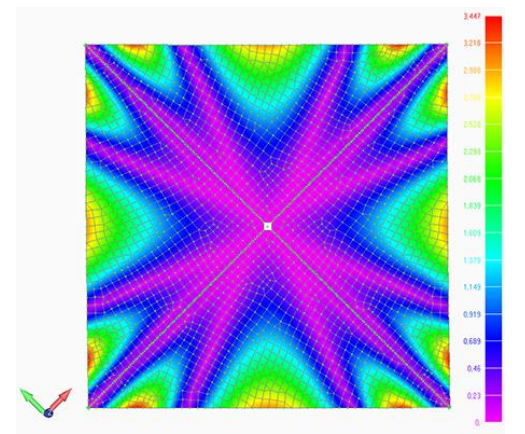

Рисунок 3 - Распределение деформаций на поверхности паруса

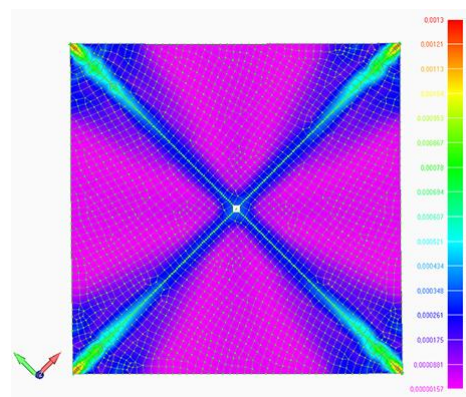

Рисунок 4 - Распределение напряжений на поверхности паруса 


\section{Заключение}

В данной работе проведено конечно-элементное моделирование конструкции космического аппарата с солнечным парусом. Создана конечноэлементная модель, на которую действует давление солнечного света. Величина давления соответствует давлению солнечного света на орбите Земли. Проведён нелинейно-статический анализ конструкции, по результатам которого были выявлены значения максимальной деформации в 3,447 мм и максимального напряжения 1,3 кПа. По результатам исследования сделан вывод, что солнечный парус способен выполнять свои функции на рабочей орбите под влиянием возмущающих факторов. 
Khabibullin Roman Maratovich

Samara National Research University, Samara, Russia

\section{Finite-Element Method in Strength Prediction of Frame-Type Solar Sail}

Abstract. The paper considers a finite-element method for strength calculation of a solar sail spacecraft. Geometric model and finite-element model of the solar sail spacecraft are created. The manuscript describes perturbative forces that influence on the sail. Also a non-linear static analysis of theframe-type solar sail spacecraft is provided.

Keywords: spacecraft, solar sail, finite-element method, finite-element simulation, strength prediction. 


\section{Литература:}

1. Olga Starinova, Irina Gorbunova, "Analytical control laws of the heliocentric motion of the solar sail spacecraft", 2014.

2. В.Л. Рвачев. Геометрические приложения алгебры логики. Киев:изд-во «Техника», 1967.

3. С. К. Годунов, В. С. Рябенький.Разностные схемы (введение в теорию), учебное пособие., М.: изд-во «Наука», 1977.

4. Чернявский А. О. Метод конечных элементов. Основы практического применения [Текст]. - 106 с.

5. «Femap: Siemens PLM Software - Россия» [Электронный ресурс] / - Официальный сайт компании Siemens Global Website - Режим доступа: http://www.plm.automation.siemens.com/ru_ru/products/femap. 